about 500 miles long. A glacier, centred at $A$, slowly pushes its way southward. . . ." To a reader familiar with the subject it is clear that this hypothetical case is a very simplified version of the glaciation of either North America or Europe. The deductions as to the features of glaciated land are similarly begun from diagrams of theoretical, imagined surfaces which are equally recognizable as generalizations (for example, Figs. 190, 201, 205), each of which is followed by specific examples of the feature discussed.

This kind of treatment may well give the student the impression that our knowledge of the phenomena is obtained from such hypotheses. In fact, as the authors well know, what happened was (1) the observation and record of a large number of facts, (2) comparison and classification of these, (3) the development of possible hypotheses for the generalization and 'explanation' of the facts, (4) the testing of the hypotheses by further observation and survey and, where possible, experiment; and only those hypotheses which have survived this testing are now accepted. While it is true that no text-book can set these steps out in full over the whole of its fields, it would be better to follow this order, so as to leave the student with the knowledge that a scientific hypothesis, or theory, is to be judged by the success with which it fits both the facts it was devised to 'explain' and any other relevant facts which may come to light later. Hence if a better hypothesis is devised, the less satisfactory one will be abandoned. Physical geography contains abundant material for such study; and, as a teashing method, it may well be preferred to the presentation of present-day hypotheses as if they are unquestioned truths.

The book is very well illustrated and produced. Although it is a first edition, the present reviewer has noticed no important error or misprint. The appendixes are, for the most part, useful; but Appendix D, "The Interpretation of Maps", does not add anything to what the pupil should know before reaching this stage; while the seven maps which conclude the volume are quite inadequate to illustrate the work although their presence may be regarded as suggesting that the reader does not need an atlas.

C. B. FAWCETT.

\section{THE SOCIOLOGY OF MEDICINE}

\section{Medicine and Mankind}

By Arnold Sorsby. Pp. $256+16$ plates. (London : Faber and Faber, Ltd., 1941.) 12s. 6d. net.

$\triangle$ DVANCES in medicine and the allied sciences $A$ have of recent years been very great; it is no exaggeration to say that the change both actual and potential in only one generation of time has been exceptional. This increase in degree and direction of knowledge cannot be wholly regarded as technical detail interesting to the practising physician in the conduct of his profession; it comes, on the contrary, directly within the concern of the intelligent man in the street, for the prevention and treatment of disease are matters which impinge immediately upon his personal life. Immunization against diphtheria may be cited as an example; it is now an established method, easy in performance and satisfactory in practice, yet it has been carried out in Great Britain on a scale which can only be described as petty compared with the extent practised in the United
States. The difference is almost entirely due to the respective efficiencies of the campaigns bringing the matter to the notice of the general public.

It is not only advantageous in his private life that the ordinary man should have some knowledge of these developments, it is important from a social point of view; public opinion has to be educated to appreciate the trend and movement of work which steadily intrudes more and more into all aspects of human life. For good or ill, man has become a community animal. Civilization brings manifold consequences; it means responsibility as well as advantages. Measures for communal welfare are not brought to efficiency by being placed upon the statute book, but by the active support of an educated public.

Books, therefore, which seek to bring anyone of matriculation standard in touch with the current findings, purposes and possibilities of modern science deserve an important place. "Medicine and Mankind" is of this type. Dr. Sorsby succeeds admirably in the picture he gives of present-day medicine. $\mathrm{He}_{\theta}$ is greatly aided in this task by the adoption of a simple straightforward design which allows balance and proportion in the subject-matter.

Dr. Sorsby, opening with an account largely historical of the relations between health and disease and the theses which have governed our attitude at different stages of progress, goes on to a statement of health from the physical point of view. He then proceeds to discuss in sequence the ill-formed body, the ill-balanced body, the abused body and the assaulted body. This enables him to set out in due proportion such diverse subjects as experimental embryology, endocrinology, dietetics, including the accessory food factors, the new dye-stuff medication, allergy and bacteriology. Treatment equally has its place and is conveniently divided into chapters on individual and collective measures.

Under the heading "Social Achievements and Frustrations" Dr. Sorsby takes up various aspects of morbidity, mortality, environment, nutrition, occupation and related factors of importance; this is perhaps his best chapter. While he directs attention to the persistence of many preventable conditions, he avoids polemics on the culpable aspect, for there are, of course, environmental conditions to-day the continuation of which infers ignorance or inattention on the part of responsible public opinion.

Dr. Sorsby is obviously interested in the special problems appertaining to nature and nurture. $\mathrm{He}$ therefore allows himself rather more space on questions of genetics and environment, but as these subjects represent an active fringe of medicine, active in its justifiable inferences as well as its real or immediate effects, this latitude cannot be regarded as altogether out of place. He omits all reference to psychological matters. This depends apparently upon a question of space, but the omission in a sense enhances the value of the book. For it allows a restriction of the contents to purely physical aspects which certainly offer enough to think about.

"Medicine and Mankind" is a competent and careful study. It should be of use to the practising physician anxious to keep in touch with the broad lines of thinking medicine; it should also be of use to the man in the street with sufficient intelligence to appreciate his limitations. There are numerous illustrations which have been happily chosen to simplify the subject-matter and enhance its application.
Joseph Geoghrgan. 